\title{
El mundo como una manzana en la palma de la mano: el pomo y su relación con la cartografía medieval ${ }^{*}$
}

\author{
Sandra SÁENZ-LóPEZ PÉREZ \\ Instituto de Historia (Dpto. Historia de la Ciencia), CSIC \\ sandra.saenz-lopez@cchs.csic.es
}

\section{RESUMEN}

Este artículo centra su atención en el pomo - una insignia de poder con la que se recrea el mundo en manos del soberano- y, concretamente, en la vinculación que durante la Edad Media mantuvo con la geografía y la cartografía en su concepción formal y simbólica. Dada la escasez de ejemplares conservados, se recurrirá a fuentes iconográficas, ya que es en imágenes de emperadores, reyes y también de Cristo como el Salvador, donde el orbe se presenta como un elemento definidor de la retratística del poder medieval.

Palabras clave: pomo, regalia insignia, Edad Media, mapa, Claudio Ptolomeo, Henricus Martellus Germanus, Cristo Salvador.

\section{The world as an apple on the hand: the orb and its relationship with me- dieval cartography}

\begin{abstract}
This article focuses on the orb -an insignia of power that situates the world in the hands of the sovereign-, and the connection that it had in the Middle Ages with geography and cartography, both in form and symbolism. Due to the shortage of preserved examples, iconographic sources will be relied upon, as it is within portraits of emperors, kings and also Christ as the Savior where the orb appears as a defining element of the medieval image of power.
\end{abstract}

Key words: orb, regalia insignia, Middle Ages, map, Claudius Ptolemy, Henricus Martellus Germanus, Christ the Savior.

* La autora quiere agradecer a Marta Serrano Coll los interesantes comentarios que de ella recibiera durante la realización de este artículo, así como a Therese Martin sus orientaciones previas. 


\section{El mundo es esférico, como una manzana}

El pomo, también referido como manzana (del latín pomum), orbe o globo, forma parte del repertorio de regalia insignia que define la simbólica del poder en la Edad Media ${ }^{1}$. Su forma redonda evoca el mundo que se deposita en manos del soberano para que lo proteja y gobierne, y ese mundo es, efectivamente, esférico. La idea de la esfericidad de la Tierra, atribuida a Pitágoras (ca. 585-ca. 495 a.C.) por el historiador griego Diógenes Laercio (siglo III d.C.) en sus Vidas, opiniones y sentencias de los filósofos más ilustres (VIII, 15), perduró prácticamente de forma continua a lo largo del Medievo ${ }^{2}$. Muchos mapas medievales representan la Tierra como circular y plana por la dificultad que supuso la conquista gráfica de la tercera dimensión y porque a la hora de cartografiar el mundo, solamente se ilustraba la pequeña porción terrestre que emergía de una esfera mayoritariamente compuesta de agua ${ }^{3}$. El monje franciscano Matfre Ermengaud (fl. 1288-1322) afirmaba en su Breviario de amor (1288-1292) que

"El agua del mar ciñe y cubre la tierra por todas partes excepto por una, que Dios nos dejó para que podamos habitar en ella. Y, en comparación, la parte que el agua deja al descubierto es muy pequeña, tan pequeña como lo que sobresaldría de una manzana metida en el agua. Y la parte de la tierra tiene venas de agua que la atraviesan, pues de otro modo se secaría en exceso y se convertiría en polvo"4.

Es decir, la tierra es como una manzana que flota en el agua ${ }^{5}$. La traducción científica de esta imagen cósmica podría tener su eco en representaciones como la que

1 En el Medievo, las insignias de soberanía, entre las que figura el pomo, fueron referidas como potestatis fasces, indumenta regalia, insignia regalia, tal como recoge O. PÉREZ MONZÓN, "Iconografía y poder real en Castilla: las imágenes de Alfonso VIII", Anuario del Departamento de Historia y Teoría del Arte, 14 (2002), p. 36, nota 108. I.G. BANGO TORVISO rechaza el término generalizado de regalia, y propone el de regalia insignia, que aquí seguimos, en "Regalia insignia: las señas de identidad del monarca y su linaje", Alfonso X El Sabio, Murcia, 2009, pp. 42-52.

2 Dentro de la amplia bibliografía referente a la esfericidad del mundo en la Edad Media, véase R. SIMEK, "The Earth as the Protected Centre of a Finite Universe and the Earth as the Yolk in the Cosmic Egg" y "The Shape of the Earth", Heaven and Earth in the Middle Ages. The Physical World before Colombus, Woodbridge, 1996, pp. 6-23 y 24-38, respectivamente, y "Sphère ou disque? La forme de la Terre", Dossier pour la science, 37 (2003), pp. 32-36. Existieron sin embargo ciertas excepciones, especialmente desde el ámbito religioso, que defendieron la planitud del mundo. Así lo hicieron Lactancio (ca. 260-ca. 320), un escritor cristiano de origen norteafricano, en sus Instituciones divinas (III, 24), y el viajero, teólogo y geógrafo bizantino Cosmas Indicopleustes (siglo VI) en su Topografía cristiana (esp. Libros II y IV).

3 Para la relación de agua y tierra en el mundo medieval, véase K.A. VOGEL, "Das Problem der relativen Lage von Erd- und Wassersphäre im Mittelalter und die kosmographische Revolution", Mitteilungen der Österreichischen Gesellschaft für Wissenschaftsgeschichte, 13 (1993), pp. 103-143; y S. GANDZ, "The Distribution of Land and Sea on the Earth's Surface According to Hebrew Sources", Proceedings of the American Academy for Jewish Research, 22 (1953), pp. 23-54.

4 A. FERRANDO y V. MARTINES, "Traducción", Breviari d'amor de Matfre Ermengaud: (Biblioteca Nacional de Rusia, Isp. F.v. XIV.N1): libro de estudios, [s.1.], 2007, p. 295.

5 Los manuscritos iluminados del Breviario de amor de Matfre Ermengaud incorporan la representación de la esfera de la tierra flotando en la esfera del agua; véase C. MIRANDA GARCÍA-TEJEDOR, "Los manuscritos con pinturas del Breviari d'amor de Matfre Ermengaud de Béziers. Un estado de la cuestión", J. YARZA, La miniatura medieval en la Península Ibérica, Murcia, 2007, pp. 313-373; e "Iconografía del 
figura en la copia manuscrita de finales del siglo XIV del Tratado de la Esfera (siglo XIII) de Johannes de Sacrobosco ${ }^{6}$ (Fig. 1), donde queda patente que la esfera de la tierra (en el centro del universo) no comparte el mismo centro que la esfera del agua (la siguiente inmediata), de forma que parece flotar, dejando emerger parte de ella.

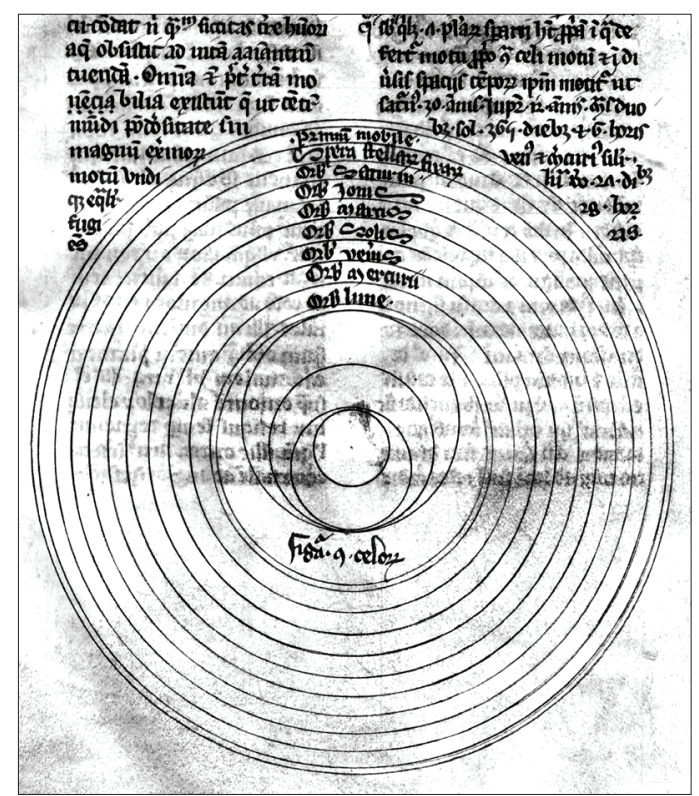

Fig. 1. Diagrama del universo en una copia manuscrita de finales del siglo XIV del Tratado de la Esfera (siglo XIII) de Johannes de Sacrobosco. Biblioteca de la Universidad de Salamanca (Ms. 2662, fol. 8v).

La esfericidad de la tierra, e igualmente su símil con una manzana, fueron reiterados por el enciclopedista francés Gautier o Gossouin de Metz (siglo XIII), quien sugería un hipotético viaje alrededor del mundo en su Image du monde:

"La tierra es redonda, y si no hubiera obstáculos, un hombre podría recorrerla, como una mosca circula alrededor de una manzana; dos hombres podrían separarse, marchando en direcciones opuestas, uno hacia el Este, otro hacia el Oeste, de forma que se reencontrarían en las antípodas"?.

\footnotetext{
'Breviari d'amor'. Escorial, Ms. S.I.3, Madrid, Biblioteca Nacional, Ms. Res. 203”, Tesis Doctoral, Madrid, Universidad Complutense de Madrid, 2002, vol. 1, pp. 463-465.

6 Biblioteca Universitaria de Salamanca (Ms. 2662, fol. 8v).

7 Traducción a partir de la edición francesa de O.H. PRIOR (ed.), L'image du monde de maître Gossouin. [También atribuido a Gautier de Metz.] Rédaction en prose. Texte du manuscrit de la Bibliothèque nationale, fonds français No. 574, avec corrections d'après d'autres manuscrits, Lausana- París, 1913, pp. 93-94; para otra edición francesa de este texto, véase Ch.-V. LANGLOIS, La vie en France au Moyen âge du XIIe au milieu du XIVe siècle, III: La connaissance de la nature et du monde d'après les écrits français à l'usage des laïcs, París,1927, pp. 164-165.
} 


\section{El pomo, insignia de soberanía}

Como las restantes insignias de soberanía, principalmente junto con las vestiduras, la corona y el cetro, el pomo tiene su origen y fundamento en la etiqueta imperial roma$\mathrm{na}^{8}$. Emperadores romanos, y por extensión dioses del panteón clásico, fueron retratados con el mundo en la mano. Este gesto y el objeto en sí pasaron a la Edad Media para definir el poder de nobles, reyes y emperadores, y también de la divinidad. En esta transmisión de la Antigüedad al Medievo, el pomo y la forma de sostenerlo experimentaron una serie de transformaciones. Frente a la preeminencia alcanzada por otras insignias -por ejemplo el cetro, que era portado en la mano derecha como signo jerárquico de distinción-, el pomo adquirió un estatus inferior, pues era colocado generalmente en la mano izquierda y podía ser utilizado por las soberanas ${ }^{9}$. Además, pasó a estar coronado por una cruz y/o flor de lis, símbolos ambos del mundo cristianizado que el soberano, en calidad de vicario de la divinidad, debía preservar ${ }^{10}$. Así se desprende, por ejemplo, de los Castigos e documentos del rey don Sancho IV, un tratado castellano destinado a la educación del príncipe heredero de finales del siglo XIII, en el que se describen las regalia insignia de "vn rey muy noble", entre las que se incluye un pomo que, nótese, está referido como "manzana":

"En la su mano siniestra tenie vna mançana redonda toda de oro, e encima de la mançana, vna cruz de oro. E la mançana es a semejança del regno que deue tener el rey en su mano e apoderarse del" 11 .

A pesar de ser un elemento habitual en la retratística del poder en la Edad Media, son muy escasos los ejemplares de pomos medievales que han llegado a la actualidad y, además, dentro de la Europa medieval, no alcanzaron la misma popularidad en todos los territorios. Fue sin duda en el Sacro Imperio Romano Germánico donde los soberanos se identificaron de forma más clara con esta insignia y, consecuentemente, son muchos los pomos germanos conservados y muy numerosos los retratos de emperadores que los exhiben. Frente a esto, en los reinos franceses e hispánicos el pomo tardó en cobrar importancia ${ }^{12}$, despuntando en cierta medida la Corona de Aragón,

8 Para el pomo, véase el excelente trabajo de P.E. SCHRAMM, Sphaira, globus, reichsapfel: wanderung und wandlung eines herrschaftszeichens von caesar bis zu Elisabeth II, Stuttgart, 1958.

9 Véase M. SERRANO COLL, "Iconografía de género: los sellos de las reinas de Aragón en la Edad Media (siglos XII-XVI)", Emblemata, 12 (2006), pp. 15-52; y "Los signos del poder: regalias como complemento a los emblemas de uso inmediato", Emblemata, 17 (2011), p. 141.

10 C. DELGADO VALERO concedió a la flor de lis de las insignias de soberanía un significado cristológico en "La corona como insignia de poder durante la Edad Media" y "El cetro como insignia de poder durante la Edad Media”, Arte hispano-musulmán (artículos). Homenaje a Clara Delgado Valero, Madrid, 2001, pp. 549-564 y pp. 565-579. Inicialmente, el primero de estos artículos fue publicado en Anales de Historia del Arte, 4 (1993-1994), pp. 747-763 y el segundo, en Actas del X Congreso del CEHA, Los clasicismos en el arte español, Madrid, 1994, pp. 45-52.

11 A. REY (ed.), Castigos e documentos para bien vivir ordenados por el rey don Sancho IV, Bloomington, 1952.

12 P.E. SCHRAMM, Las insignias de la realeza en la Edad Media española, Madrid, 1960, pp. 63 y 126-128, para el caso del pomo en Castilla; y I.G. BANGO TORVISO, "De las insignias reales en la España 
donde se introdujo en la coronación de Pedro II en 1204, cuando el papa Inocencio III le otorgó este símbolo en detrimento de los derechos antes exclusivos del emperador ${ }^{13}, \mathrm{y}$ donde cobró especial importancia a partir de Pedro IV el Ceremonioso $(1336-1387)^{14}$.

Los pomos medievales llegados a la actualidad son mayoritariamente aquellos que formaban parte del ajuar funerario de emperadores y reyes, quienes habitualmente se hacían enterrar con sus insignias de soberanía, generalmente no las originales, sino copias de las que habían utilizado en vida. Así por ejemplo, según recogen Jerónimo Zurita en los Anales de la Corona de Aragón y, posteriormente, Jerónimo de Blancas en las Coronaciones de los reyes y reinas de Aragón, el rey Fernando I de Aragón, muerto en 1416, había pedido en su testamento (dictado en Perpiñán, el 10 de octubre de 1415), ser enterrado con vestiduras e insignias reales - entre las que figuraba el pomo-, semejantes a aquellas con las que había sido coronado ${ }^{15}$.

Pomos con cruz de remate han sido encontrados en los sarcófagos de emperadores del Sacro Imperio Romano Germánico, como Enrique III (m. 1056) ${ }^{16}$, Lotario II o III (m. 1137) ${ }^{17}$ o Segismundo (m. 1437) ${ }^{18}$, así como en el de Rodolfo I, rey de Bohemia (m. 1307) ${ }^{19}$. Igualmente interesante para los pomos funerarios es el grabado con los restos del emperador Federico II Hohenstaufen (m. 1250), realizado por Francesco Daniele durante la apertura del sarcófago en las labores de restauración de la Catedral de Palermo entre 1781 y 1799, y publicado en I regali sepolcri del Duomo di Palermo riconosciuti ed illustrati, Nápoles, 1784. La imagen muestra que el cuerpo del soberano fue embalsamado y enterrado con sus correspondientes insignias -vestimenta, corona, espada y el orbe-; este último, descrito por el propio Daniele como "il pomo o globo di metallo, mancante però della sua croce; e trovossi pieno di terra" ${ }^{20}$, parece haber caído rodando junto a la cabeza del difunto.

Otros pomos también del Sacro Imperio Romano Germánico fueron ilustrados en un grabado de Johann Adam Delsenbach realizado en Núremberg en $1751^{21}$. Fue en esta ciudad alemana donde se depositaron, entre 1424 y 1796, gran parte de lo que actualmente se conoce como el Tesoro del Reich o Imperial (las insignias imperiales

medieval", M.L. MELERO MONEO, et alii (eds.), Imágenes y promotores en el arte medieval. Miscelánea en homenaje a Joaquín Yarza Luaces, Barcelona, 2001, p. 66.

13 P. E. SCHRAMM, op. cit., 1960, p. 129.

14 Para el estudio del monarca en la Corona de Aragón y de su recurso al pomo como insignia regia véanse los trabajos ya citados de M. SERRANO COLL, así como su Tesis Doctoral, "La imagen figurativa del rey de Aragón en la Edad Media", Tarragona, Universitat Rovira i Virgili, 2005.

15 Véase J. DE BLANCAS, Coronaciones de los reyes y reinas de Aragón, Zaragoza, 1641, pp. 90-91.

16 Museo Diocesano de Espira, Alemania.

17 Herzog Anton Ulrich-Museum, Braunschweig, Alemania.

18 Historisches Museum, Budapest.

19 Catedral de San Vito, Praga. Para estos y otros pomos funerarios, véanse las ilustraciones en P.E. SCHRAMM, op. cit., 1958, tafel 31, abb. 61a y 61b; tafel 31, abb. 62; tafel 40, abb. 81c; y tafel 43, abb. 89a.

20 VV.AA., Il sarcofago dell'imperatore, Palermo, 2002, vol. 2; F. DANIELE, I regali sepolcri del Duomo di Palermo (reproducción de la $2^{\mathrm{a}}$ ed., Nápoles, 1859), p. 106.

21 Dicho grabado fue publicado por DELSENBACH en el Wahre Abbildung der sämtlichen Reichskleinodien..., Núremberg, 1790. Esta imagen está digitalizada en <http://www.bildindex.de/ obj00111714.html\#|home> (última consulta: 14 de enero de 2013). 
de los reyes de los pueblos germánicos y emperadores del Sacro Imperio Romano Germánico), concretamente el grupo llamado Nürnberger Kleinodien (las joyas de Núremberg). En el grabado de Delsenbach figura el anverso y reverso de Der Reichsapfel, el pomo imperial más importante conservado de la Edad Media, conocido por su nombre ("el orbe") en alemán, realizado posiblemente en Colonia en el siglo XII para la coronación de Enrique VI (en 1191) o Felipe de Suabia (en Mainz, 1198), o para un rival de este último, Ottón IV de la dinastía de Welf (en Aquisgrán, 1198) ${ }^{22}$. Junto a este figuran en el grabado otros dos pomos desaparecidos. A pesar de la aparente semejanza de los tres, un cotejo detallado revela interesantes diferencias, tanto en el cuerpo esférico como en las cruces de remate.

Una apreciación semejante de diferencias formales en pomos ilustrados es la que plantea Amadeo Serra Desfilis en su estudio del rollo genealógico de la Corona de Aragón (ca. 1410), conocido como la Genealogía de Poblet por conservarse hoy en la biblioteca de ese monasterio. Este investigador señala que la cruz del pomo del rey Martín I el Humano (1396-1410) es muy diferente de las cruces de Sobrarbe que coronan los orbes de sus predecesores, con lo que "este detalle abre el interrogante de si la cruz, casi flordelisada más que patada, pudiera ofrecer la imagen de una nueva pieza del tesoro real destinada a reemplazar la que había pertenecido a Pedro el Ceremonioso" 23. Otro detalle de la Genealogía de Poblet, concretamente el arrepentimiento que muestra que el iluminador, una vez concluido el retrato del conde de Barcelona Ramón Berenguer IV, borró los florones de su tocado para transformar con ello una corona real en condal (en una garlanda o diadema ricamente decorada) ${ }^{24}$, parece avalar la fidelidad de esta obra en la representación de las insignias, lo que, consecuentemente, reafirma la idea de que las diferencias de los orbes no respondían a la imaginación del artista, sino a una copia de la realidad. Es interesante notar, por otra parte, que el conde de Barcelona figure con un orbe crucífero en su mano izquierda, lo que sería interpretado en este caso como símbolo de soberanía, es decir, no como una insignia regia, pues no se corrigió como sí lo fue la corona real.

\section{El pomo tripartito de "T en O": origen y evolución}

Si miramos con estos mismos ojos la variedad de pomos ilustrados existentes en las artes figurativas de la Edad Media, podríamos plantear que las diferencias formales no son mero artificio decorativo de los autores de esas imágenes, sino que responden a una evocación de distintos modelos. De todos ellos, el más frecuente es el que denominaremos a partir de ahora "pomo tripartito". La insistencia de su representación en manos de emperadores, reyes, nobles y también de la divinidad, así como la abun-

\footnotetext{
22 Kunsthistorisches Museum, Viena, Weltliche Schatzkammer (n. ${ }^{\circ}$ inv. SK WS XIII 2). Para una imagen e información de esta insignia, véase http:/www.kaiserliche-schatzkammer.at/en/visit/collections/seculartreasury/selected-masterpieces/ (última consulta: 14 de enero de 2013).

23 A. SERRA DESFILIS, "La historia de la dinastía en imágenes: Martín el Humano y el rollo genealógico de la Corona de Aragón”, Locus amoenus, 6 (2002), p. 69. La cursiva es mía para enfatizar.

24 Este arrepentimiento, apreciado por E. TORMO, Las viejas series icónicas de los reyes de España, Madrid, 1916, p. 61, fue reiterado por M. SERRANO COLL, op. cit. 2011, pp. 132-133.
} 
dancia de ejemplares suntuarios llegados de entre las regalia insignia de los siglos posteriores -desde el XVI hasta la actualidad ${ }^{25}$-, hace sospechar que este tipo de insignia hubiera existido ya en la Edad Media, aunque no se haya conservado ninguno de ellos. Quizá ya habrían desaparecido del Tesoro Imperial germánico cuando en 1751 Johann Adam Delsenbach hizo su grabado de las joyas de Núremberg, pues el libro de reliquias Wie das hochwirdigist..., realizado en 1487 también en Núremberg (donde, como decíamos, se guardaban esas regalia insignia), sí incorpora una entalladura en la que hacen su aparición dos de estos pomos tripartitos ${ }^{26}$.

El pomo tripartito resulta de dividir horizontalmente la esfera por la mitad y nuevamente una de estas mitades entre dos, de forma vertical. En su concepción formal guarda una muy estrecha relación con las fuentes cartográficas medievales, concretamente con los mapas esquemáticos tripartitos de "T en O" (Fig. 2). La "T" es una representación estilizada de los tres canales hídricos que separan los tres continentes entonces conocidos: el brazo horizontal izquierdo es el Tanais (Río Don), el derecho el Nilo y el astil vertical el Mar Mediterráneo ${ }^{27}$; la "O" es el océano circundante que abraza la tierra, como si de un río se tratara. Asia se localiza en la mitad superior y en la inferior, Europa a la izquierda y África a la derecha. Estos mapas están orientados en el sentido literal de la palabra, es decir, Oriente se dispone arriba, en la parte preeminente según la jerarquía espacial medieval cristiana. El protagonismo que acapara este continente se debe a que es por donde sale el sol -astro íntimamente asociado a la divinidad ${ }^{28}$ - y donde se encuentra el paraíso terrenal, tal como está recogido en Génesis (II, 8) y como muestran muchos mapas medievales ${ }^{29}$. Aunque la concepción del mundo tripartito y esas divisiones naturales de los tres continentes tienen su origen en la Antigüedad ${ }^{30}$, estas nociones geográficas se asimilaron en la Edad Media con el relato bíblico del reparto del mundo entre los tres hijos de Noé -Sem, Jafet y Cam- tras el diluvio universal ${ }^{31}$. Por ello, muchos de estos mapas aluden textual y gráficamente a esta distribución de las tierras y a quienes fueron sus herederos ${ }^{32}$.

Los mapas de "T en O" son, de toda la cartografía medieval, los más numerosos cuantitativamente y los que mayor popularidad alcanzaron en el tiempo: los más antiguos que conservamos están datados en los siglos VII-VIII y continuaron reali-

25 Por ejemplo, Isabel II de Inglaterra portó este tipo de pomo en su coronación el 2 de junio de 1953.

26 Bayerische Staatsbibliothek, Múnich (4 Inc.c.a. 514). Este incunable está digitalizado en $<$ http://dfg-viewer.de/show/?set $\% 5 \mathrm{Bmets} \% 5 \mathrm{D}=\mathrm{http} \% 3 \mathrm{~A} \% 2 \mathrm{~F} \% 2 \mathrm{Fdaten}$.digitale-sammlungen. $\mathrm{de} \% 2 \mathrm{~F} \sim \mathrm{db} \% 2 \mathrm{Fmets} \% 2 \mathrm{Fbsb} 00011304$ mets.xml> (última consulta: 5 de febrero de 2013 ).

27 J.T. LANMAN defiende una vinculación entre la "T" y la cruz de Cristo en "The Religious Symbolism of the T in T-O maps", Cartographica, 18:4 (1981), pp. 18-22; para una aproximación a los mapas de "T en O”, véase L.S. CHEKIN, Northern Eurasia in Medieval Cartography: Inventory, Texts, Translation, and Commentary, Turnhout, 2006, pp. 27-74.

28 Por el Este sale el sol, el astro creado por Dios antes que al hombre para que iluminara el mundo (Génesis, 1:16), y Dios es identificado con la luz según Juan (8:12).

29 Véase A. SCAFI, Mapping Paradise. A History of Heaven on Earth, Londres, 2006.

30 Véase por ejemplo POMPONIO MELA, Corografia (1:8) (siglo I).

31 Génesis (9:18-10).

32 Véase C. VAN DUZER y S. SÁENZ-LÓPEZ PÉREZ, "Tres filii Noe diviserunt orbem post diluvium: The World Map in British Library Add. MS 37049”, Word \& Image, 26:1 (2010), pp. 21-39. 

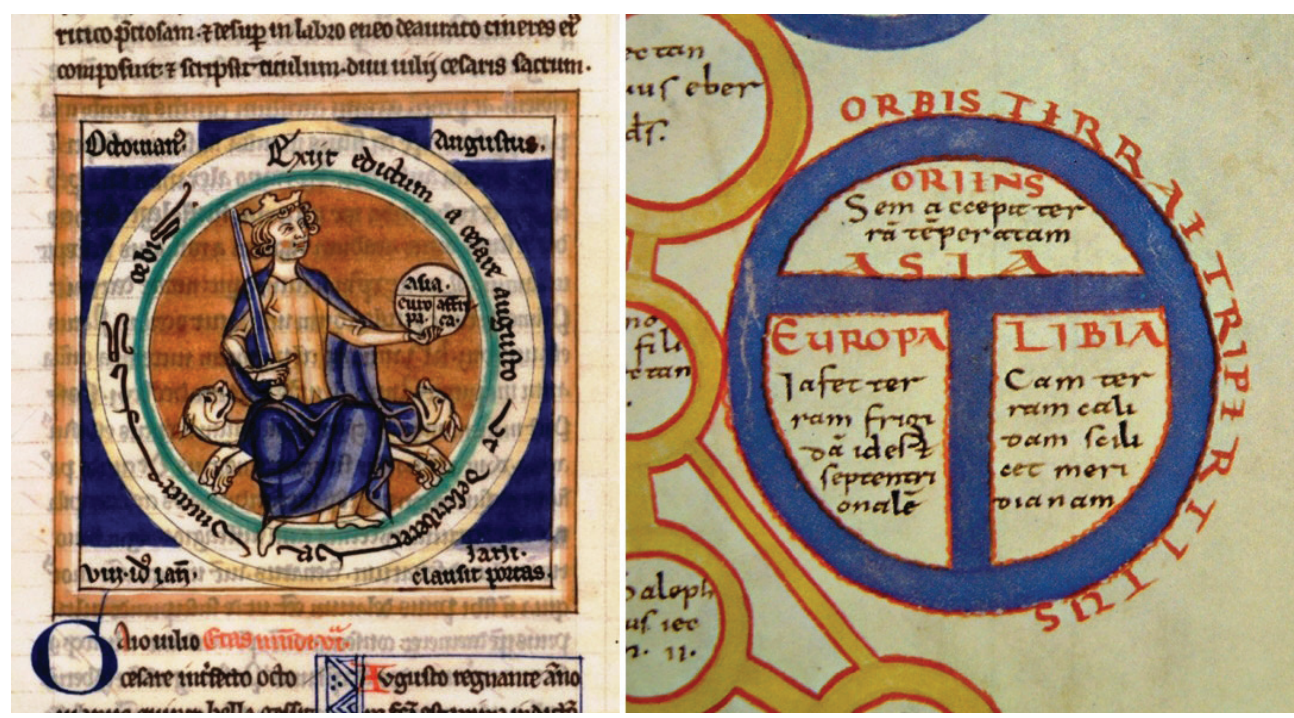

Fig. 2. Izquierda: El emperador Augusto con un orbe tripartito de "T en O" en la mano, en el Liber floridus de Lambert de Saint-Omer (ca. 1250-1275). Bibliothèque nationale de France, París (Ms. lat. 8865, fol. 45r). Derecha: Orbis terrae tripartitus (mapa de "T en O") del Beato de Saint-Sever (tercer cuarto del siglo XI). Bibliothèque nationale de France, París

(Ms. Lat. 8878, fol. 7r).

zándose a lo largo de toda la Edad Media ${ }^{33}$. Su auge influyó en la imagen del mundo simbolizada en el pomo, hasta el punto de que podríamos hablar de "pomo tripartito de 'T en O'”. Entre los muchos ejemplos existentes en las artes figurativas medievales señalaremos dos de ellos significativos por su variado enfoque: el emperador Augusto aparece retratado en un manuscrito del Liber floridus de Lambert de Saint-Omer (ca. 1250-1275) con un orbe de "T en O" en su mano izquierda (Fig. 2), donde se indican, como en los mapas, los nombres de los tres continentes (Asia, Europa y Affrica) ${ }^{34}$. Igualmente, con un orbe de "T en O" figura Cristo Niño a hombros de San Cristóbal en el retablo de este santo realizado en el siglo XIV ${ }^{35}$. En este caso, la tripartición del mundo evoca el aire (el cielo con el sol, la luna y estrellas), el agua (peces) y la tierra (castillos), algo que igualmente encontramos con cierta frecuencia en mapas medievales, por ejemplo, en la representación del mappamundi de la tumba de Darío del Alexander in

\footnotetext{
33 Aparece en la edición impresa de las Etimologías de San Isidoro realizada en Augsburgo en 1472 por Günther Zainer, y es el primer mapa impreso.

34 Bibliothèque nationale de France, París (Ms. lat. 8865, fol. 45r).

35 Museo Nacional del Prado (n. ${ }^{\circ}$ cat. P03150). La imagen está digitalizada en $<\mathrm{http}: / /$ www.museodelprado. es/coleccion/galeria-on-line/galeria-on-line/obra/retablo-de-san-cristobal/> (última consulta: 5 de febrero de 2013)
} 
historienbijbel (Utrecht, 1467) ${ }^{36}$, donde esos tres elementos de la naturaleza están a la vez asociados con los nombre de los tres hijos de Noé $^{37}$.

Tal es la relación entre este modelo cartográfico y esta insignia de soberanía que en muchos casos se llegó a reiterar en esta última la aparente planitud del mundo que evocan las imágenes cartográficas. Muchas otras imágenes medievales del mundo tripartito supieron simular el sentido esférico de la Tierra, otorgando a la " $\mathrm{T}$ " una forma tridimensional. Así ocurre en la imagen del poeta inglés John Gower (ca. 1330-1408) disparando flechas a una esfera en un manuscrito de su Vox Clamantis (Voz del Profeta) de 13991408 ${ }^{38}$ : nuevamente la esfera tripartita encarna tres de los elementos naturales (aire, tierra y agua). Esta misma esfericidad aparece en algunos pomos ilustrados, muy especialmente a partir del siglo XV y del desarrollo de la pintura flamenca. La técnica al óleo permitía representar mediante un sistema de veladuras una esfera cristalina, que a su vez, permitía transparentar la parte posterior de la "T" tridimensional. Así aparece, por ejemplo, en el Salvator mundi (ca. 1500-1510) del pintor flamenco Quentin Massys ${ }^{39}$ o, dentro del ámbito hispano-flamenco, en el Salvador de Pedro Berruguete (ca. 1490) ${ }^{40}$ (Fig. 3).

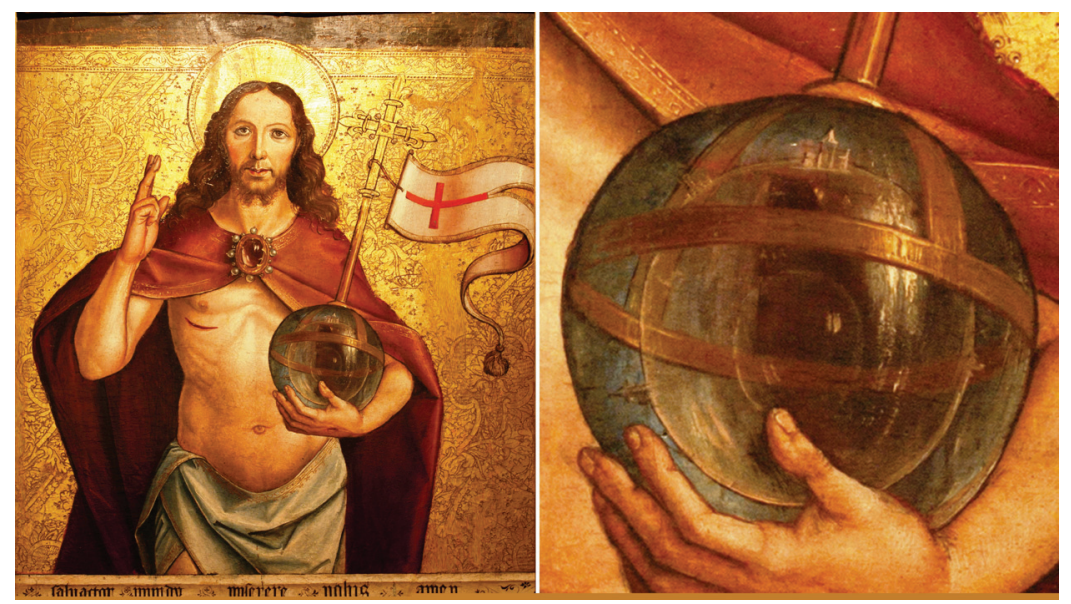

Fig. 3. Cristo Salvador del mundo de Pedro Berruguete (ca. 1490) con un orbe tripartito en la mano. Museo Diocesano de Palencia (n. ${ }^{\circ}$ inv. IIC-4-120-002-0010). Fotografía: Antonio Rubio López (Palencia).

36 Koninklijke Bibliotheek (Biblioteca Real), La Haya (Ms. 78 D 39, fol. 370r). La imagen está digitalizada en $<$ http://manuscripts.kb.nl/zoom/BYVANCKB\%3Amimi_78d39\%3A370v_min> (última consulta: 5 de febrero de 2013). Para los mapas de la tumba de Darío en los manuscritos ilumināos del Alexander in historienbijbel, véase N.R. KLINE, Maps of medieval thought: the Hereford paradigm, Woodbridge, 2003, p. 178.

37 La tierra, el agua, el aire son, recordemos, tres de los cuatro (junto con el fuego) elementos del mundo sublunar artistotélico, que heredó la cosmología medieval como se puede apreciar en el universo de Sacrobosco (Fig. 1).

38 University of Glasgow, Special Collections (Ms. Hunter 59, fol. 6v). La imagen está digitalizada en $<$ http:// special.lib.gla.ac.uk/manuscripts/search/detail_c.cfm?ID=34369> (última consulta: 5 de febrero de 2013).

39 North Carolina Museum of Art, Estados Unidos (K-1688). La imagen está digitalizada en <http:// library.artstor.org/library/ExternalIV.jsp?objectId=8DtZYyMmJloyLyw7eDt5R34o $>$ (última consulta: 5 de febrero de 2013).

40 Museo Diocesano de Palencia (nº inv. IIC-4-120-002-0010). 
Pero esas imágenes esféricas de cristal no deben de ser entendidas como meros alardes técnicos de la pintura flamenca al óleo, sino como evocaciones de la concepción medieval del universo, en la que se sintetizan las ideas aristotélicas y ptolemaicas y la teología cristiana. El universo era concebido esférico, finito y geocéntrico. La Tierra, compuesta de las sustancias materiales tierra, agua, aire y fuego, estaba ubicada en el centro y a su alrededor, ocho esferas homocéntricas con los planetas conocidos (incluidos el sol y la luna) y las estrellas fijas, hechas de una sustancia cristalina y transparente, giraban gracias al Primum mobile o Primer motor ${ }^{41}$ (Fig. 1). Ese universo cristalino es pues el que reproducen las pinturas anteriores en manos de la divinidad. Y si bien sobre el cristal esférico de Massys se reflejan edificios y torres típicamente flamencos, que quizá evocan el mundo habitado o el lugar de realización de esta obra ${ }^{42}$, la esfera de Berruguete deja además entrever otra esfera en su interior, sobre la que se levantan esquemáticas imágenes de ciudades, y que podríamos identificar con la Tierra ${ }^{43}$.

Asimismo, es interesante señalar que, tal como se aprecia en estos pomos, con el tiempo, la " $T$ " - ese convencionalismo geográfico con el que se dividía el mundo en tres continentes y se daba preeminencia a Asia- se invierte, muy probablemente para convertirla en estructura de soporte de la cruz, con la que se coronan los orbes. Esta inversión de la " $T$ " trajo consigo una pérdida de la resonancia cartográfica original de los mapas de "T en O". Solo así se explica que estos pomos alcanzaran gran éxito a partir del siglo XVI, cuando la tradicional división tripartita del mundo entró en crisis a raíz del descubrimiento de América ${ }^{44}$.

\section{El pomo geográfico y la cartografía del siglo XV}

Así pues, a medida que la historia se aproxima hacia su modernidad, la referencia geográfica y el sentido simbólico de la "T en O" del pomo tripartito se van desvaneciendo. Pero las conexiones de esta insignia con la geografía y la cartografía no desaparecen, sino que se materializan en otro modelo de pomo, al que llamaremos "pomo geográfico", por primar en su concepción formal un dibujo más realista del mundo. Detrás de ese realismo geográfico se encuentran los avances cartográficos que tuvieron lugar en Florencia en el siglo XV y que determinaron el final de la

41 Para una aproximación a la cosmología medieval, véase R. SIMEK, op. cit.; E. EDSON, Medieval Views of the Cosmos, Oxford, 2004.

42 Considero interesante recoger otro ejemplo semejante que aparece en una pintura alemana de Cristo bendiciendo con donante y su familia (1575-80) del Metropolitan Museum of Art, Nueva York (17.190.1315), donde se muestra el orbe tripartito con la imagen de la ciudad de Hamburgo en su interior, posible origen de la familia. La imagen está digitalizada en <http://www.metmuseum.org/toah/works-of-art/17.190.13-15> (última consulta: 5 de febrero de 2013).

43 Esta misma imagen de la Tierra contenida dentro del universo cristalino aparece en otras pinturas contemporáneas, como el orbe en manos del Cristo bendiciendo (1494-1496) de Fernando Gallego del Museo Nacional del Prado ( $\mathrm{n}^{\circ}$ cat. P02647). La imagen está digitalizada en $<\mathrm{http} / / \mathrm{www}$.museodelprado.es/coleccion/ galeria-on-line/galeria-on-line/obra/cristo-bendiciendo/> (última consulta: 5 de febrero de 2013).

44 La imagen esférica de la Tierra y su representación en época moderna será abordado en un futuro trabajo. 
cartografía medieval y el nacimiento de la moderna. Por un lado, la recuperación en Occidente de la Geografia de Claudio Ptolomeo (ca. 100-ca. 170), llegada a Florencia a finales del siglo XIV entre los manuscritos traídos de Constantinopla por Manuel Chrysoloras, y traducida al latín por este y por Jacopo Angeli (1406-1409) ${ }^{45}$. La gran popularidad alcanzada por esta obra ptolemaica radica en que explicaba, por primera vez de forma científica, cómo proyectar una esfera sobre una superficie plana y, consecuentemente, cómo hacer mapas. Paradójicamente, la Geografía de Ptolomeo acabó resultando no solo útil para trasladar la esfera al plano, sino también para recrear la imagen tridimensional del mundo sobre un soporte bidimensional ${ }^{46}$, en definitiva, para el tema que aquí nos interesa: la representación de la Tierra en los pomos u orbes ilustrados. En la preocupación artística por mostrar gráficamente la llamada "tercera proyección", donde el geógrafo griego se cuestiona "de qué modo puede representarse en un plano el hemisferio visible de la Tierra contenido bajo una esfera armilar" (Libro 7, cap. 6) ${ }^{47}$, un autor anónimo incorporó entre 1503-1516 una imagen que resolvía esta cuestión en un manuscrito florentino de la Geografía de Ptolomeo, realizado hacia $1470^{48}$ (Fig. 4): sobre la esfera de la Tierra se proyecta un mappamundi ptolemaico, en el que solamente se cartografía el mundo conocido (el resto queda en blanco $)^{49}$. Esta solución artística a la tercera proyección fue tan solo superada en 1525 por Alberto Durero, autor de la correspondiente imagen en la edición impresa de Willibald Pirckheimer, realizada en Estrasburgo en $1525^{50}$. En su grabado, Durero se ajustó más a las leyes de la perspectiva al disminuir la distancia entre los meridianos según aumentaba su distancia respecto del ojo del espectador, creando así el artificio de un globo tridimensional.

Como protagonista destacado de la cartografía del siglo XV hay que hacer, por otro lado, mención a Henricus Martellus Germanus, un cartógrafo que vivió y trabajó en Florencia entre 1480 y 1496, y que hacia 1489 o 1490 realizó un mappamundi que, aunque deudor de la influencia ptolemaica, adquirió personalidad propia: renunció al océano Indico ptolemaico como un mar interior, y al hacerlo, rompió la unión de

45 Para la Geografía de Ptolomeo, véase P. GAUTIER DALCHÉ, La Géographie de Ptolémée en Occident (IVe-XVIe siècle), Turnhout, 2009; y Z. SHALEV y C. BURNETT (eds.), Ptolemy's Geography in the Renaissance, Londres, 2011.

46 Al respecto, debemos de señalar la vinculación que existió entre la Geografía de Ptolomeo y la perspectiva lineal, descubierta por Filippo Brunelleschi hacia 1410; véase S.Y. EDGERTON Jr., "Florentine Interest in Ptolemaic Cartography as Background for Renaissance Painting, Architecture, and the Discovery of America", Journal of the Society of Architectural Historians, 33:4 (1974), pp. 275-292; y A. CATTANEO, "Map Projections and Perspective in the Renaissance", Z. SHALEV y C. BURNETT (eds.), op. cit., 2011, pp. 51-80.

47 C. PTOLOMEO, Cosmografia de Ptolomeo, Burgos, 2010, p. 263.

48 Bibliothèque nationale de France, París (Ms. Latin 4801, fol. 74r).

49 D. BUISSERET, La revolución cartográfica en Europa: 1400-1800. La representación de los nuevos mundos en la Europa del Renacimiento, Barcelona, 2004, Lámina VI.

50 El ejemplar de esta edición de la Biblioteca Nacional de España, Madrid (GMG/1051) está digitalizado en <http://bibliotecadigitalhispanica.bne.es:80/webclient/DeliveryManager?pid=3156056\&custom att_2=simple_viewer $>$ (última consulta: 5 de febrero de 2013). Aunque el grabado no está firmado por Durero, su autoría está confirmada gracias a la correspondencia mantenida entre Pirkheimer y Johann Tscherte, arquitecto imperial en Viena, donde se menciona esta esfera y afirma que ha sido realizada por Alberto Durero, amigo común de ambos; véase T. S. MOORE, Albert Durer, Whitefish, 2004, pp. 77-78. 

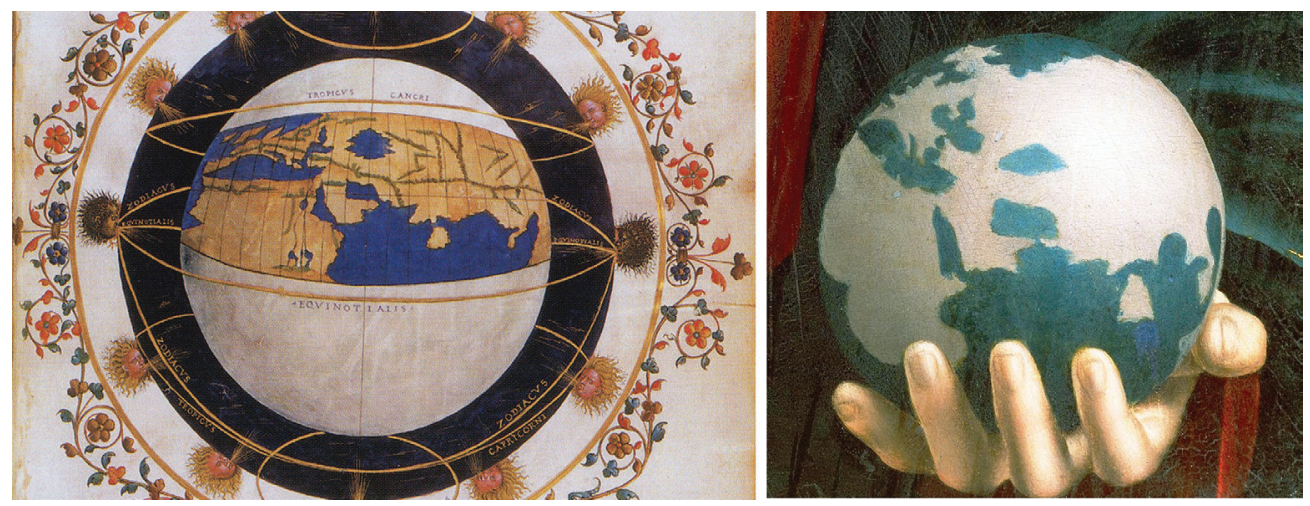

Fig. 4. Izquierda: Detalle de la ilustración anónima de la esfera armilar realizada entre 15031516 en un manuscrito florentino de la Geografía de Ptolomeo de ca. 1470. Bibliothèque nationale de France, París (Ms. Latin 4801, fol. 74r). Derecha: Detalle del orbe que sostiene en su mano el Salvator mundi de Marco d'Oggiono (ca. 1500). Galleria Borghese, Roma (n. ${ }^{\circ}$ inv. 435).

Asia y África, diseñó el Extremo Oriente con la llamada “cola de dragón” y dibujó el contorno completo de África, alusivo a su circunnavegación, que enfatizó rompiendo con su extremo sur el enmarcamiento del mapa ${ }^{51}$.

La influencia de las cartografías de Claudio Ptolomeo y de Henricus Martellus Germanus se hace presente en el primer globo terráqueo conservado, obra del alemán Martin Behaim (1492) ${ }^{52}$. Muy similar en su imagen geográfica es el orbe que sostiene en su mano el Salvator mundi de Marco d'Oggiono (ca. 1500) ${ }^{53}$, donde a los elementos de la tradición ptolemaica, como la localización de la triangular Trapobana (Sri Lanka) en el ecuador, se suman otros martellianos: Asia con "cola de dragón" o África completamente circunnavegada (Fig. 4). También similar es el orbe con el que un personaje, quizá el propio Claudio Ptolomeo, aparece retratado por Rafael Sanzio en La escuela de Atenas (1509-1512) de la Stanza della Segnatura de los Palacios Vaticanos. Por último, estos rasgos definidores de la cartografía moderna se dejan sentir con mucha claridad en el pomo de coronación de Eric XIV rey de Suecia (1561) ${ }^{54}$, que aunque conserva la estructura tripartita de la "T en O" se ha desprendido ya de la reminiscencia cartográfica medieval (Fig. 5).

51 Para una aproximación a Henricus Martellus Germanus, véase E. EDSON, The World Map, 1300-1492: The Persistence of Tradition and Transformation, Baltimore, 2007, pp. 215-219.

52 Germanisches Nationalmuseum, Núremberg (n. ${ }^{\circ}$ inv. WI 1826). Para esta obra, véase el clásico, de aún gran vigencia, E.G. RAVENSTEIN, Martin Behaim, his life and his globe, Londres, 1908.

53 Galleria Borghese, Roma ( $\mathrm{n}^{\circ}$ inv. 435).

54 Tesoro del Palacio Real, Estocolmo. Resulta también interesante el "pomo geográfico" con la "T en O" invertida que sostiene en sus manos el Cristo Salvador en una pintura de un seguidor de Leonardo da Vinci de hacia 1510, conservada en el Museo de Bellas Artes de Nancy (n. ${ }^{\circ}$ inv. 28). Para este orbe, véase V. DROGUET y T. CRÉPIN-LEBLOND (eds.), Le Roi et l'Artiste. Françoise ler et Rosso Fiorentino, París, 2013, p. 59. Gracias a Francisco de Asís García, por señalarme la existencia de este cuadro. 


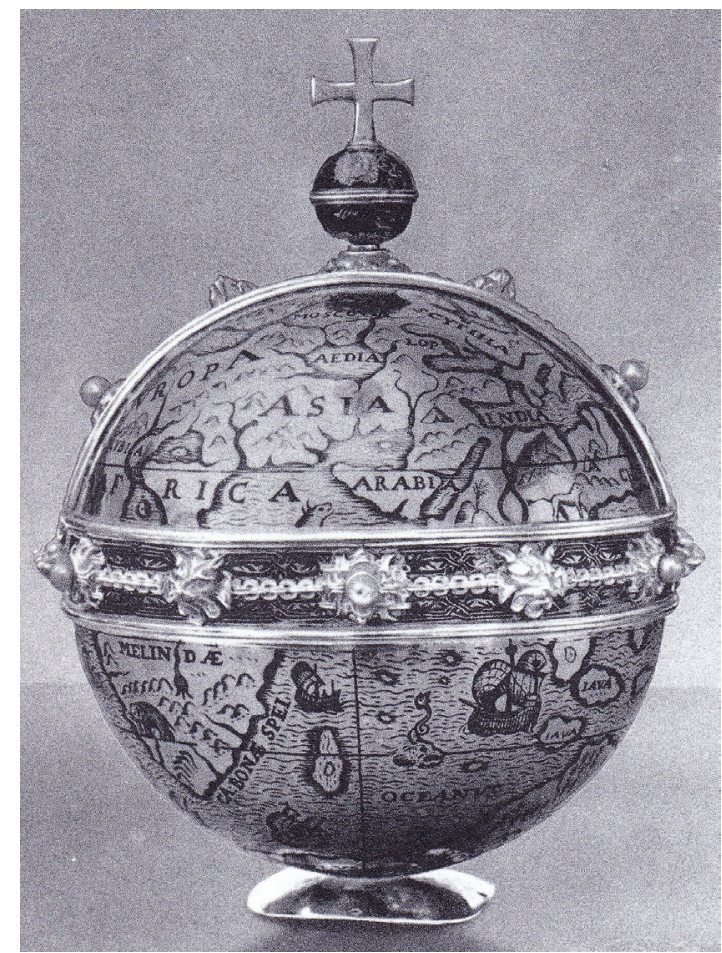

Fig. 5. Pomo de coronación de Eric XIV rey de Suecia (1561). Tesoro del Palacio Real, Estocolmo.

\section{A modo de conclusión}

A lo largo de la historia, emperadores, reyes, nobles y la divinidad han sostenido el mundo en su mano en un gesto eterno que, traspasando toda connotación política, supo evocar tan bien el poeta inglés William Blake en su Auguries of innocence (Augurios de inocencia) de hacia 1803:

To see a World in a Grain of Sand And a Heaven in a Wild Flower Hold Infinity in the palm of your hand And Eternity in an hour ${ }^{55}$.

55 D.V. ERDMAN (ed.), The Complete Poetry \& Prose of William Blake, Berkeley-Los Angeles, 2008, p. 490. Gracias a Elisa Garrido, por llamarme la atención de estos versos. 